\title{
A Review of on-Board Integrated Electric Vehicles Charger and a New Single-Phase Integrated Charger
}

\author{
Tuopu Na, Xue Yuan, Jiaqi Tang, and Qianfan Zhang
}

\begin{abstract}
To avoid weight, size and cost constraints, on-board integrated charging devices use the traction system components. In this paper, the topologies of on-board integrated electric vehicles (EVs) chargers are reviewed. The topologies of on-board integrated chargers can be classified into three groups based on the integrated components. The first type is that only converter is integrated as one part of the on-board charger. While the grid side also needs filter inductors. The second group is based on the switched reluctance motor, which can integrate both the converter and the motor windings into the on-board charger. This is followed by the integrated charger based on permanent magnet motor (PM) and induction motor (IM). The last group also integrates both the converter and the motor windings. Then this paper gives a new single-phase on-board integrated charger based on $\mathrm{AC}$ motor. Parts of inverter are used as single-phase rectifier, parts of inverter coupled with one capacitor and inductor reconstruct an active power filter (APF) circuit, and the motor windings are used as grid-side filter inductors. As the existence of APF circuit, the proposed integrated charger can eliminate the second harmonic ripple and the quasi-Z-source network just need small capacitor and inductor to suppress ripples. Using the proposed topology, the motor can keep still in charging mode. A $2.2-\mathrm{kW}$ prototype is designed to give the experimental results.
\end{abstract}

Index Terms-Active power filter (APF), integrated charger, quasi-Z-source.

\section{INTRODUCTION}

C HARGER is an important part of EVs system. EV charger can be classified into off-board charger and on-board charger in [1]. On-board charger is more convenient for customers, because customers can charge the EVs anywhere. While, on-board charger is inside the EVs. It takes much space, increases the weight of EVs and costs much. To solve these problems, an idea about integrating EVs' motor windings or traction system or both motor windings and traction system components into on-board charger is proposed. Because the traction system of the EVs includes inverter with three IGBT bridges, current sensors, voltage sensors and control circuits.

Manuscript received July 14, 2019; revised September 1, 2019; accepted September 9, 2019. Date of publication December 30, 2019; date of current version November 12, 2019. This work was supported by the National Natural Science Foundation of China (51877055) and Project 2018YFB0104602 by the National Key Research and Development Program of China. This paper was presented in part at the 2019 IEEE 10th International Symposium on Power Electronics for Distributed Generation Systems (PEDG), Xi'an, China, June 2019.

All authors are with the Electrical Engineering Department, Harbin Institute of Technology, Harbin, China (email: natuopu@126.com; 470641821@ qq.com; tang_jiaqi@outlook.com; zhang_qianfan@hit.edu.cn).

Digital Object Identifier 10.24295/CPSSTPEA.2019.00027
The hardware of traction system can work as functions of three bridges rectifier, single-phase PFC and so on. And the charging mode and traction mode of EVs operate in different time. So we can consider using the hardware of traction system to reconstruct a charger. The inverter can work as a rectifier and DC/DC converter can realize buck function in charging mode. Even the motor windings can be used as the grid-side filter inductors or an inductor in DC/DC converter by reconstructing the windings. Additional components may be needed to realize some functions in charging mode. When the motor windings and traction system are integrated into a charger, the weight, size and cost of on-board charger reduce. While, the integrated charger has some disadvantages, such as, the motor maybe rotates in charging mode, the charging power will be limited by the traction system. And the single-phase integrated charger has a problem that dc-side exists second harmonic ripples. The voltage ripple in dc-side is suppressed by a large capacitor or additional components.

This paper introduces the topologies of on-board integrated charger for EVs. And a new single-phase integrated charger is proposed which can suppress the second harmonic ripple. The proposed system only needs a small additional capacitor and inductor. The paper is organized as follows. In Section II, the overview of integrated charger is given. Three groups including DC/DC converter, switched reluctance motor and alternating current motor are discussed respectively. A novel single-phase integrated charger based on AC motor is proposed in Section III. The operation of system is analyzed in detail. The experimental results are given in Section IV. Section V gives a conclusion.

\section{Topologies of INTEgRated Charger}

Many topologies of integrated EV chargers have been proposed in recent years. In [2], the topologies of integrated EV chargers are classified into three groups, as shown in Fig. 1. The first group just integrates DC/DC converter into the system. The $\mathrm{DC} / \mathrm{DC}$ converter is reconstructed and rectifying function or a new converter is realized in charging mode. The second group integrates the switched reluctance motor into the EV charger. The reconfigured SRM can perform function of DC/ DC converter and rectifier. The last group integrates alternating current motor into the charger, and it can be classified into four kinds, that is integrating just one three-phase motor, multiple motors, multiphase motor and open-end winding motor. The following will discuss the details of all classifications. 


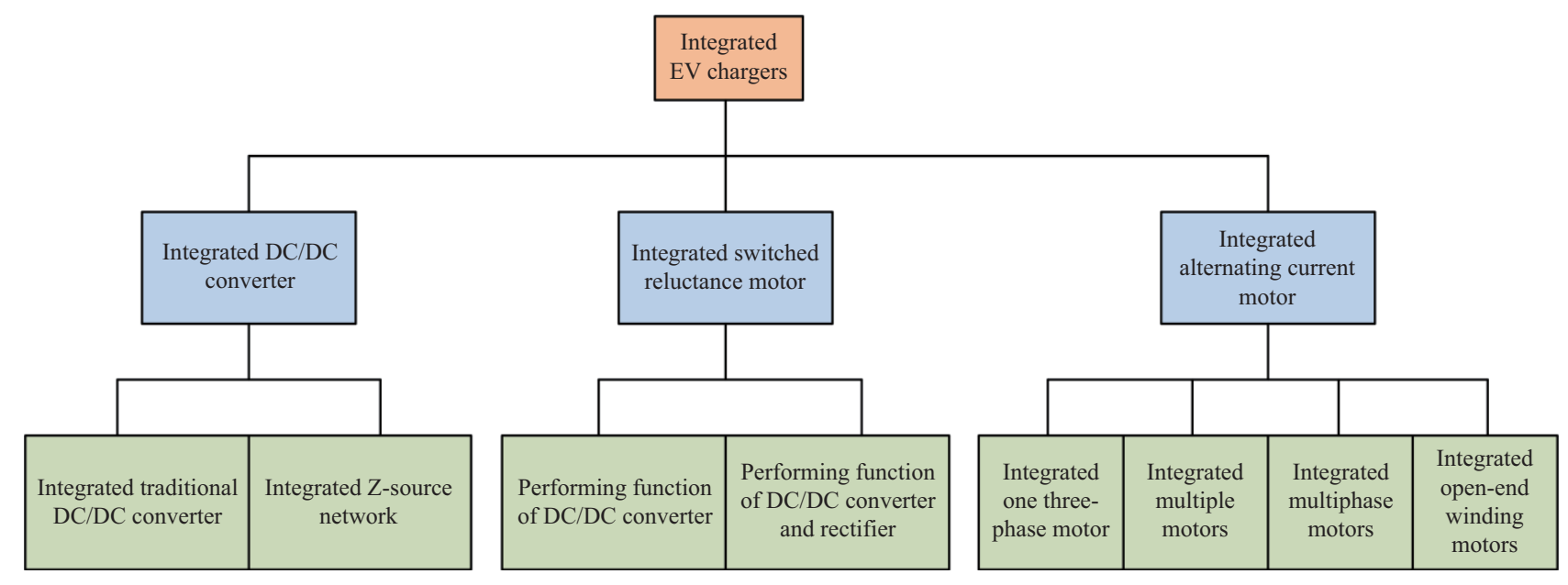

Fig. 1. Integrated EV chargers classification.

\section{A. Using the DC/DC Converter}

\section{1) Traditional DC/DC Converter}

In this part, only traditional DC/DC converter is integrated as parts of on-board charger. In [3]-[5], DC/DC converter can be utilized as a new converter by adding some components, as shown in Fig. 2. The disadvantage is that, a uncontrolled rectifier will be needed in charging mode. While in some integrated charger, the converters perform function of a rectifier [6], [7], as shown in Fig. 3. These topologies can achieve bi-directional power flowing, and save many devices. So the biggest advantage is that, the system costs less and the efficiency can be enhanced. Reference [8] proposes a singlephase integrated charger which can achieve V2G and reduce the second harmonic current ripple. However, the gird-side filter inductors are still needed. The inductance will be larger when the charging power is large. The size and weight of inductors increase, which take more space. All these problems are the disadvantages of this system. So the idea integrating motor windings into charger is proposed, which will be introduced in next classification. Reference [9] gives a new single stage integrated charger which reduces the numbers of components. A novel multifunctional converter is proposed in [10], which uses the least components achieving three working modes. It can perform buck/boost operation in plug-in charging, propulsion and regenerative braking mode. Active filter circuit can be constructed by low voltage battery charger's hardware without any additional components in [11]. The low-frequency harmonic current is suppressed. The disadvantage is that, the charging power is maximal with the low-voltage battery charger power. It cannot achieve fast charging.

\section{2) Z-source Network}

Z-source network is proposed by F. Z. Peng [12]. Z-source network also can be used as boost function in EVs and it is a bidirectional converter. The advantages have been given in [12]. Reference [13] proposes a modified Z-source integrated EV charger. The advantages are that it can provide isolation and the energy storage system can be integrated. But the topology is

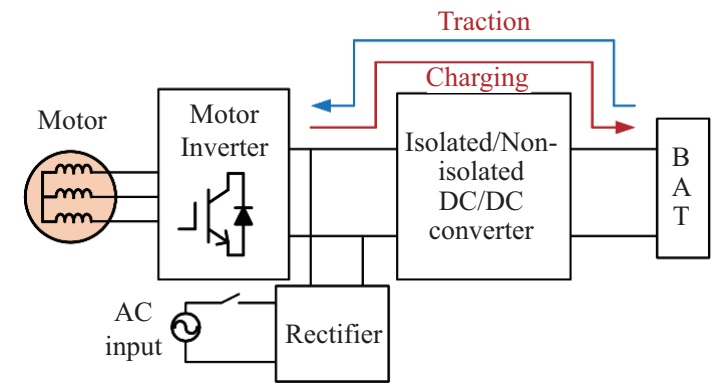

Fig. 2. Using the traditional DC/DC converter.

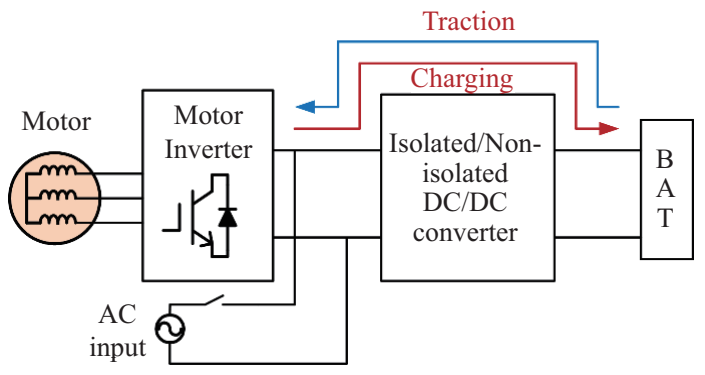

Fig. 3. Using the traditional DC/DC converter.

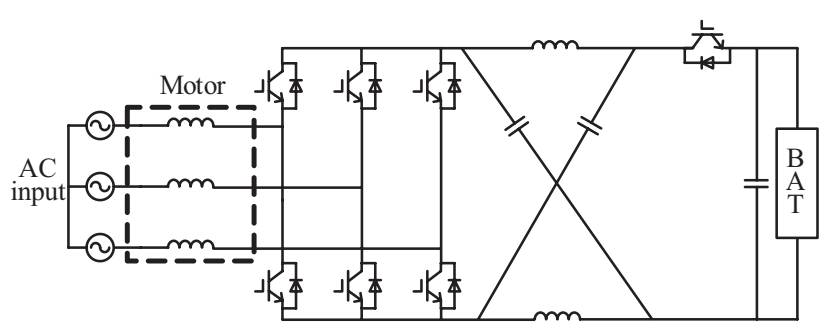

Fig. 4. Z-source integrated charger.

complex and many additional components are needed. A control method of Z-source integrated charger is proposed in [14]. No additional components are added to achieve battery charging, as shown in Fig. 4. 


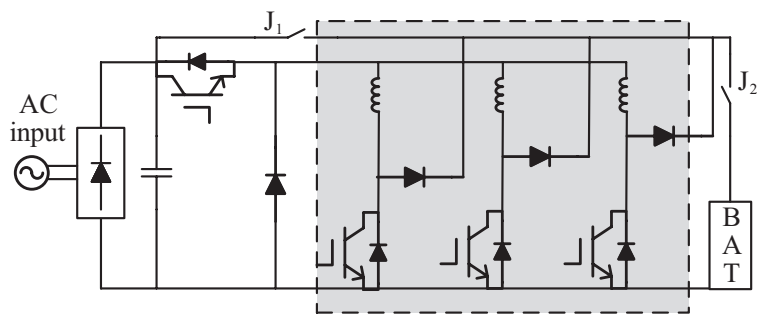

Fig. 5. SRM utilized as DC/DC converter.

\section{B. Using Switched Reluctance Motor}

\section{1) SRM Performing Function of DC/DC Converter}

Reference [15], [16] propose an integrated charger which uses SRM as a DC/DC converter, as shown in Fig. 5. Charging mode and traction mode can be achieved by changing the states of $\mathrm{J}_{1}$ and $\mathrm{J}_{2}$. By changing the switch states of IGBTs, the energy flows between the SRM, the engine generator and the battery. The SMR and the converter work as a buck-boost-type or a buck-type dc-dc converter when works in charging mode. While, the disadvantage is that many additional diodes and switches are needed.

\section{2) SRM Performing Function of DC/DC and Rectifier}

The topology which integrates one bridge of the inverter as a buck-boost converter and the other two bridges as a rectifier is proposed in [17], as shown in Fig. 6. A similar topology which can achieve the functions of G2V and V2G is proposed in [18]. The advantages of these integrated chargers are that, no dc-dc converter is needed in charging mode and the on-board charger is reconstructed easily. The cost and size of charger system decrease. But the integrated charger needs some switches to change the working mode which will decrease reliability. Multilevel converter is achieved by using the windings of a split four-phase SRM in [19]. Both DC charging and AC charging can be realized. And it combines the split converter topology with central-tapped SRM windings which can improve system reliability. But the control strategy is complex. Reference [20] utilizes the windings of the SRM as the boost inductor and buck-boost inductor during charging mode. The two stages converter can be got. The disadvantage is that too many additional diodes and switches are added. The buck and buckboost PFC chargers can be constructed by using the windings of the SRM during charging mode in [21]. The disadvantage is that the motor windings are needed to reconstruct. It has low application value.

\section{Alternating Current Motor}

\section{1) One Three-Phase Motor}

\section{a) Motor winding and converter performing function of $D C / D C$}

Reference [22] proposes one single-phase integrated charger which can achieve buck DC/DC and boost DC/DC. While, three relays are added, as shown in Fig. 7. So the system reliability decrease. Reference [23] proposes a three-phase

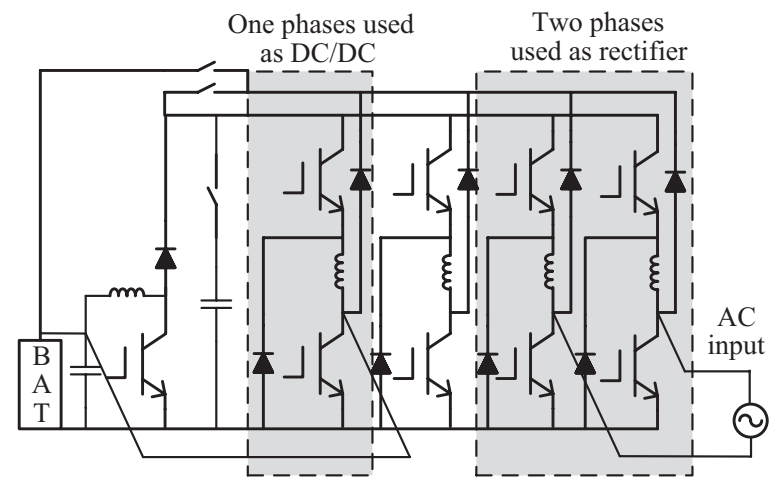

Fig. 6. SRM utilized as rectifier and DC/DC converter.

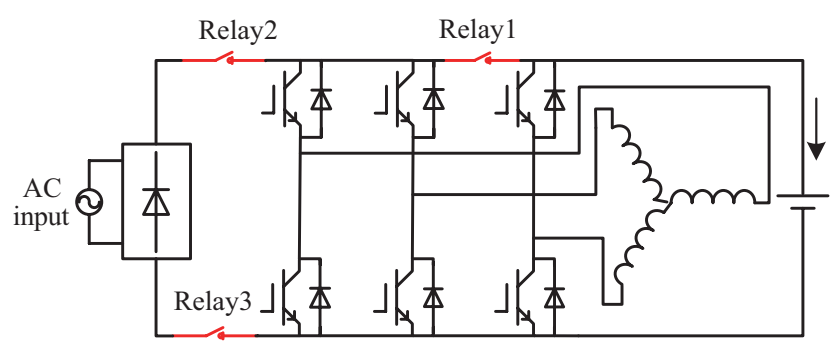

Fig. 7. Motor windings and inverter utilized as DC/DC converter.

integrated charger which connects an add-on three-phase power electronics interface to the system. A similar singlephase integrated charger is proposed in [24], which needs an additional diode bridge. The motor windings and two IGBT legs are utilized as a two-channel interleaved boost converter. The advantages of these two integrated chargers are that, the power interface is used to correct the power factor, the motor windings and inverter can regulate the battery voltage. But the system needs some additional components. A single-phase integrated PFC is proposed in [25]. The motor windings and the traction system form the charger's circuits. Two modes including buck and boost can be realized. But the harmonic input current is high. Two-stage integrated charger is reconstructed by a threephase motor and six additional switches in [26]. The biggest disadvantage is that, too many switches are added which costs much and decreases reliability.

\section{b) Motor winding and converter performing function of rectifier}

In [27], the three-phase integrated charger is based on threephase three-level NPC topology. The fast charging mode and slow charging mode are realized. While, the large grid-side filter inductors are still needed in fast charging mode. Three modes including boosting drive motor mode, directly drive motor mode and charging mode are achieved in [28]. The motor inverter is used as rectifier and motor windings are used as grid-side filter inductors. The disadvantage is that, the DC/DC converter for traction mode should be a bi-directional converter which is not necessary for a EV. A similar theory is realized in [29], as shown in Fig. 8. Three or two additional inductors are 


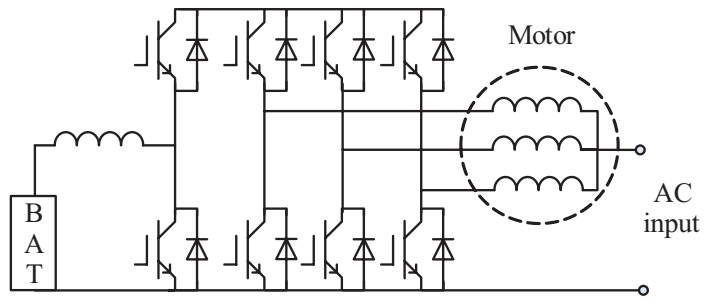

Fig. 8. Motor windings and inverter utilized as rectifier and DC/DC converter.

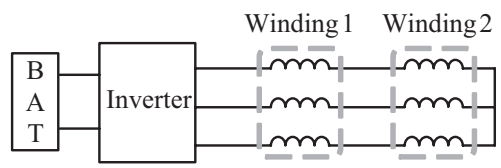

Traction mode

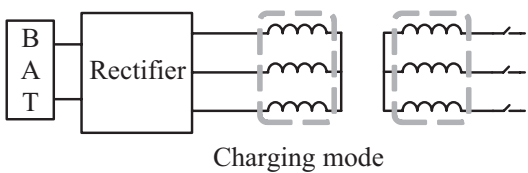

Fig. 9. Isolated integrated charger .

used to increase grid-side filter inductance in [30]. The cost and size of system increases, and several switches are needed. Reference [31] proposes a 3-phase integrated charger. The girdside current flows through the midpoint of each winding of the motor and each phase of the AC grid is connected to two parallel PWM boost converters. A similar three-phase integrated charger based on three-phase split-windings motor is proposed in [32]. Though the grid-side filter inductors are not needed, the motor windings should be reconfigured. These two methods are not practical application products. An integrated charger based on three-phase with nine windings motor is proposed in [33]. One isolated integrated charger is proposed by S. Haghbin in [34]-[36], as shown in Fig. 9. A special spilt PM is integrated into the system, the windings are served as a transformer in charging mode. But the biggest disadvantage is that, the motor will rotate in charging mode. Another isolated three-phase/ single-phase integrated charger is presented in [37]. A doublestator-winding motor is used and the windings work as filter inductors in charging mode. While, a DAB DC/DC converter and a VSI are needed to realize isolated charging.

\section{2) Multiple Motors}

A novel low cost control for two motors integrated with five bridges is proposed in [38]. In this paper, no extra components are added. But an auxiliary motor and an auxiliary inverter are needed, which costs much. Reference [39] introduces a type of integrated charger based on two motors and two set of drive systems, as shown in Fig. 10. This topology is suitable to single-phase charging system. Two additional slow recovery diodes and additional inductors are used. The phase current ripple decreases and the system efficiency increases. A similar topology is proposed in [40]. The $14 \mathrm{~V}$ accessory DC/ DC converter is also integrated into the system. This method provides isolation and this has a practical application value. Another single-phase integrated charger based on four motors is proposed in [41], as shown in Fig. 11. Two motor windings

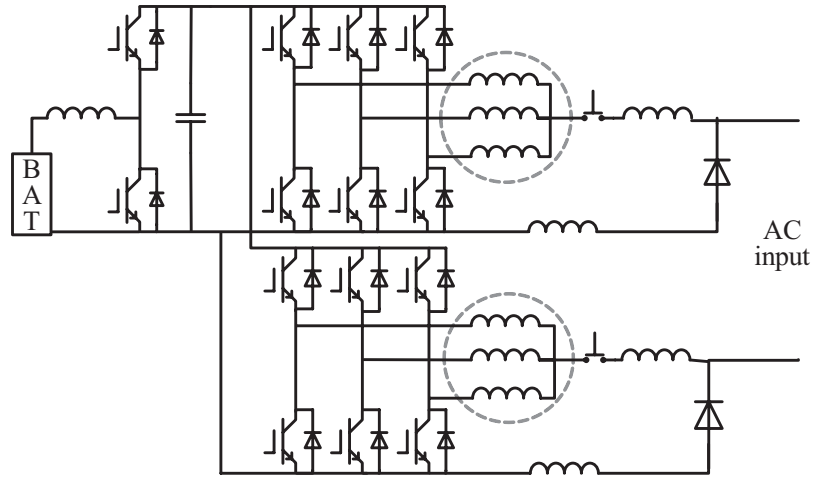

Fig. 10. Two motors integrated charger.

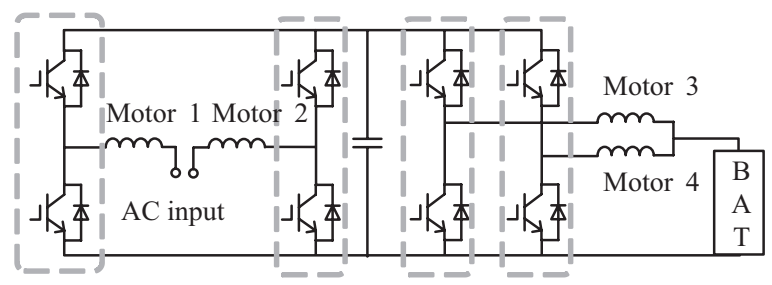

Fig. 11. Four motors integrated charger.

are used as filter inductors and two inverters are served as rectifier. The other two inverters and two windings are used as second stage DC/DC converter, which can control the output voltage. This also has a great practical application value. While, [42] proposes a three-phase integrated charger based on twomotor system. Through reconstructing the converter, there is no torque during charging mode. The disadvantages are that, the motors windings should be reconfigured and many switches are needed. A three-phase integrated charger based on four motors is proposed in [43]. During charging mode, one inverter and one motor are idle. The grid is connected to the neutral points of the other three motors. The windings of these three motors are used as filter inductors. While, the biggest problem is that, the inductance of the equivalent filter inductors is small.

\section{3) Multiphase Motors}

Five-phase motor system is integrated into a charger in [44]. Because of the motor windings reconfiguration, it is equal to three-phase windings and three IGBT legs during the charging mode. The similar theory is used to a threephase integrated charger based on six-phase motor in [45], [46], as shown in Fig. 12. These integrated charger methods have the same disadvantage, they cannot provide isolation. A transformer is needed. A three-phase integrated charger based on nine-phase motor is proposed in [47]. This topology does not need reconstructing the motor windings, the grid directly connects the natural point of each motor during charging mode. It also can achieve single-phase charging. And in [48], an asymmetrical nine-phase machine is used for integrated EV charger. The proposed system also can perform function of V2G. But the input current harmonic is very high. This is because the motor windings are in parallel. Reference [49] proposes a three-phase integrated charger based on six-phase motor. The configuration utilizes a nine-switch converter and 


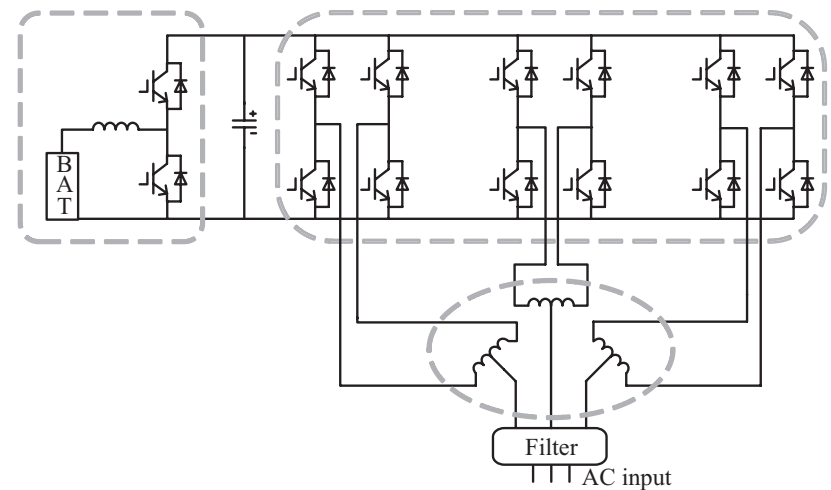

Fig. 12. Six-phase motor integrated charger.

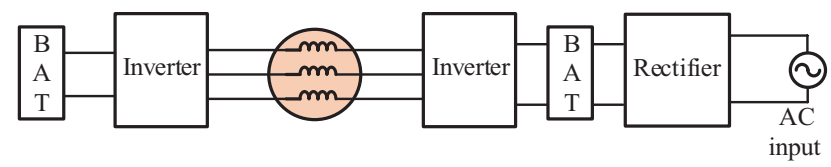

Fig. 13. Open-end winding integrated charger.

motor windings as inductors and converter. Using too many switches decreases the system reliability. An isolated threephase integrated charger based on nine-slot/eight-pole motor is proposed in [50]. During the charging mode, the motor windings are reconfigured and used as a transformer. The system needs six IGBT legs. The disadvantages of this method are that the system is too complex and the motor will rotate in charging mode. Another integrated charger based on six-phase motor is proposed in [51]. By reconfiguring the motor windings during charging mode, the windings and the inverters operate as a three-phase charger. The only problem is that many contactors are needed. In [52], a bi-directional Cuk converter is used to perform buck/boost function in traction and charging mode. The windings of asymmetrical six-phase induction machine coupled with six IGBT bridges are used as single-phase PFC. The size, weight and cost of the charger are also reduced, but the second harmonic ripples are not reduced.

\section{4) Open-End Winding Motors}

Integrated charger based on open-end winding motor is proposed in [53], [54], as shown in Fig. 13. The topology proposed in [53] can utilize windings to charge the second battery. But two batteries are used and the control method is complex. The dual-inverter of the open-end winding motor system operates as the charger in charging mode [54]. And the windings of transformer can be reconfigured as the windings of the impedance source network. One of the disadvantages is that the function switches do not make the circuit layout compact. So the parasitic parameter becomes large. The other is that the impedance and the turn number of primary windings for the magnetic combination transformer should be identical. Another open-end winding integrated charger system needs only an additional uncontrolled diode-rectifier to charge the battery [55]. No additional switches are used.

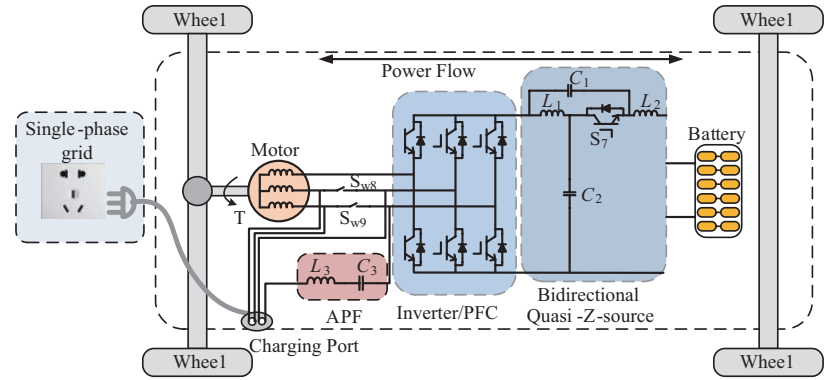

Fig. 14. Proposed single-phase integrated charger .

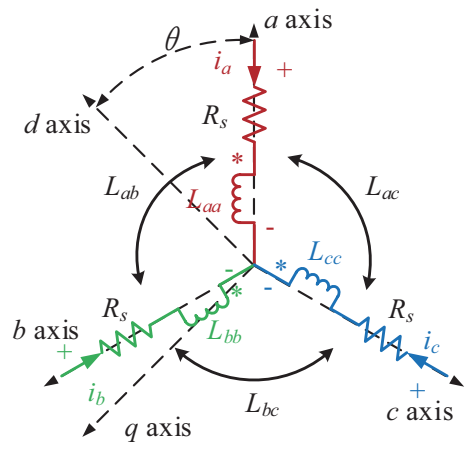

Fig. 15. Simplified equivalent electrical model.

\section{A New Single-Phase Integrated Charger Based ON AC MOTOR}

\section{A. System Functional Description}

A new single-phase integrated charger is proposed in this paper, as shown in Fig. 14. A quasi-Z-source network is used for regulating the output voltage. The quasi-Z-source network is a bi-directional system, which can realize bucking/boosting voltage.

When $\mathrm{SW}_{8}$ and $\mathrm{SW}_{9}$ are turned on, the system works in traction mode. When $\mathrm{SW}_{9}$ and $\mathrm{SW}_{9}$ are turned off, the system works in charging mode. In charging mode, the single-phase quasi-Z-source charger makes the most of traction system hardware of the EVs. The two bridges of the inverter are used as PFC, the motor windings are used as the grid-side filter inductor, and the third bridge of the inverter is coupled with one capacitor $C_{3}$ and inductor $L_{3}$ which construct the APF circuit. The size and weight of the on-board charge reduce using the proposed system. And as the single-phase inverter/rectifier exists the second harmonic ripple, the traditional single-phase system needs large capacitor to eliminate the dc output voltage ripple. While the APF used in this proposed system takes very small space and can eliminate the second order harmonic ripples.

\section{B. Electromagnetic Effect}

As the motor windings are integrated into the on-board charger, we need to do research about the electromagnetic effect. And the inductance of the motor windings should be calculated in charging mode. Fig. 15 gives the simplified equivalent electrical model of the motor when the proposed 
system works in charging mode. And $i_{a}, i_{b}$ and $i_{c}$ are the stator phase currents; $L_{a a}, L_{b b}$ and $L_{c c}$ are stator self-inductances; $M_{a b}$, $M_{b c}$ and $M_{a c}$ are the mutual inductances; $L_{d}$ and $L_{q}$ are $d$-axis and $q$-axis stator self-inductances, respectively. We assume that high order harmonic components are ignored when we analyze the inductances.

In this paper, we use three-phase surface permanent magnet synchronous motor (SPMSM). So it has $L_{d}=L_{q}$. At last, we can get the stator voltage equation

$$
\left[\begin{array}{l}
v_{a} \\
v_{b} \\
v_{c}
\end{array}\right]=R_{s}\left[\begin{array}{l}
i_{a} \\
i_{b} \\
i_{c}
\end{array}\right]+\left(L_{a a}+M_{a b 0}\right) \frac{\mathrm{d}}{\mathrm{d} t}\left[\begin{array}{l}
i_{a} \\
i_{b} \\
i_{c}
\end{array}\right]
$$

The inductance of each phase is $L_{a a}+M_{a b 0}$. When the system works in charging mode, we can calculate the $d$-axis and $q$-axis currents according to the windings connection method of the proposed system.

$$
\begin{aligned}
& i_{d}=i_{a} \cos \theta+i_{b} \cos \left(\theta-\frac{2}{3} \pi\right)+i_{c} \cos \left(\theta+\frac{2}{3} \pi\right) \\
& i_{q}=-\left[i_{a} \sin \theta+i_{b} \sin \left(\theta-\frac{2}{3} \pi\right)+i_{c} \sin \left(\theta+\frac{2}{3} \pi\right)\right]
\end{aligned}
$$

Then we can get the electromagnetic torque,

$$
T_{e}=\frac{3}{2} p\left[\frac{1}{2} \psi_{a} i_{a} \sin \theta+\frac{1}{8}\left(L_{d}-L_{q}\right) i_{a}^{2} \sin (2 \theta)\right]
$$

where $p$ is the number of pole pairs. It can be seen that, when in charging mode, the electromagnetic torque is zero. The motor will not rotate in charging mode.

\section{APF Parameters Design}

The equivalent circuit of the integrated charger system working in charging mode is shown in Fig. 16. We assume the system works with unit power factor. So the grid-side current and voltage are

$$
v_{s}=\sqrt{2} V_{s} \sin (\omega t) \quad i_{a}=\sqrt{2} I_{a} \sin (\omega t)
$$

The input power is

$p_{\text {in }}=v_{s} i_{a}-L_{a} \frac{\mathrm{d} i_{a}}{\mathrm{~d} t} i_{a}=V_{s} I_{a}-V_{s} I_{a} \cos (2 \omega t)-w L_{a} I_{a}^{2} \sin (2 \omega t)$

And we assume the capacitor voltage and the inductor current of APF are

$$
\begin{gathered}
v_{C_{3}}=V_{C_{3}} \sin (\omega t+\varphi) \\
i_{C_{3}}=I_{C} \cos (\omega t+\varphi)=\omega C_{3} V_{C_{3}} \cos (\omega t+\varphi)
\end{gathered}
$$

where $\varphi$ is the phase difference.

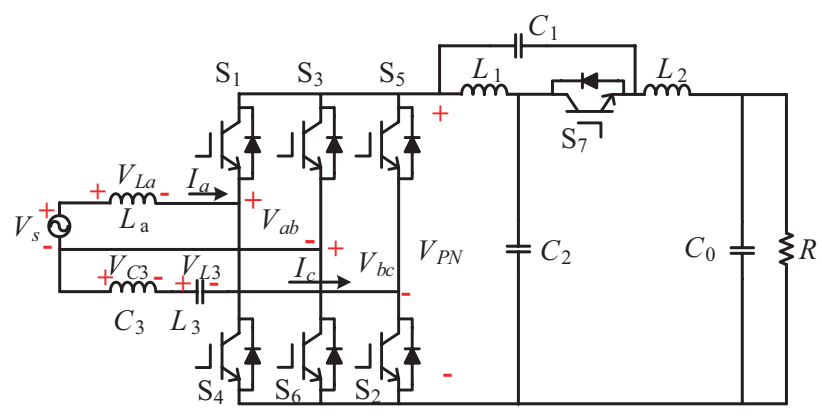

Fig. 16. Single-phase quasi-Z-source rectifier with APF.

So the power of APF is

$p_{\mathrm{APF}}=L_{3} \frac{\mathrm{d} i_{C}}{\mathrm{~d} t} i_{C}+v_{C_{3}} i_{C}=\left(\frac{1}{2 \omega C_{3}}-\frac{\omega L_{3}}{2}\right) I_{C}^{2} \sin (2 \omega t+2 \varphi)$

If the second harmonic ripple is suppressed, the power of APF should be equal to the second harmonic input power.

$$
p_{\mathrm{APF}}=-V_{s} I_{a} \cos (2 \omega t)-w L_{a} I_{a}^{2} \sin (2 \omega t)
$$

Then we can get the current and voltage of capacitor $C_{3}$.

$$
\begin{gathered}
v_{C_{3}}=\sqrt{\frac{2 \sqrt{V_{s}^{2} I_{a}^{2}+\omega^{2} L_{a}^{2} I_{a}^{4}}}{\omega C_{3}-\omega^{3} L_{3} C_{3}^{2}}} \sin (\omega t+\varphi) \\
i_{C_{3}}=\sqrt{\frac{2 \sqrt{V_{s}^{2} I_{a}^{2}+\omega^{2} L_{a}^{2} I_{a}^{4}}}{1 / \omega C_{3}-\omega L_{3}}} \cos (\omega t+\varphi) \\
\varphi=\frac{\pi}{2}+\frac{1}{2} \tan ^{-1}\left(\frac{V_{s}}{\omega L_{a} I_{a}}\right)
\end{gathered}
$$

As the inverter is integrated into one part of the charger, the inductor current and capacitor voltage of APF shouldn't be larger than the rated current and voltage of the inverter. It should have

$$
V_{b c} \leqslant \sqrt{2} V_{a b} \quad I_{c} \leqslant \sqrt{2} I_{a}
$$

According to (5), (11) and (12), we can get

$$
\begin{aligned}
& V_{a b}=\sqrt{2 V_{s}^{2}+2 \omega^{2} L_{a}^{2} I_{a}^{2}} \\
& V_{b a}=V_{C_{3}}\left(1-\omega^{2} L_{3} C_{3}\right)
\end{aligned}
$$

Submitting (15) and (16) into (14), we can get the value range of $C_{3}$,

$$
\frac{\left(1-\omega^{2} / \omega_{s}^{2}\right) \sqrt{V_{s}^{2} I_{a}^{2}+\omega^{2} L_{a}^{2} I_{a}^{4}}}{\omega V_{a b}^{2}} \leqslant C_{3} \leqslant \frac{\sqrt{2} I_{a}\left(1-\omega^{2} / \omega_{s}^{2}\right)}{\omega V_{a b}}
$$




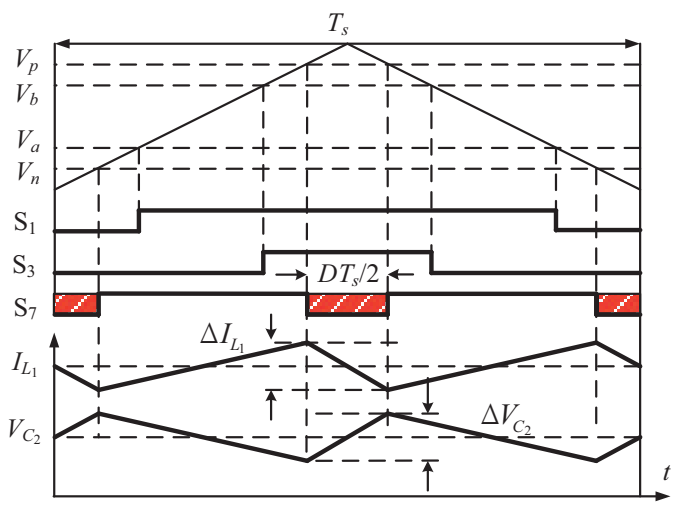

Fig. 17. Modulation and the capacitor voltage and inductor current of quasi-Zsource.

where $\omega_{s}$ is the resonant frequency of APF, $\omega_{s}=1 / \sqrt{L_{3} C_{3}}$.

It can conclude that, the $C_{3}$ and $L_{3}$ of APF can be calculated by the following steps in practical application.

1) According to the system power, grid-side input voltage $V_{s}$ and fundamental frequency, $I_{a}$ and $\omega$ are calculated.

2) Calculate the $V_{a b}$ according to (5).

3 ) As the capacitor and inductor values vary with the resonant frequency, the best resonant frequency $\omega_{s}$ should be chosen to make the size and weight of APF lowest.

4) According to (17), the value range of $C_{3}$ can be got. The final value is determined by the closest capacitance in practical engineering.

5) Calculate the $L_{3}$ from $\omega_{s}=1 / \sqrt{L_{3} C_{3}}$.

The details of the control strategy of the APF system are introduced in [56].

\section{Quasi-Z-Source Parameters Design}

As the APF is applied in single-phase quasi-Z-source rectifier, the second harmonic ripple in dc-link has been absorbed. The capacitor voltage and inductor current of quasi-Z-source network just exist high frequency ripples. So small capacitance and inductance of quasi-Z-source are able to suppress the ripples. The size and weight of quasi-Z-source network with APF are smaller than that without APF.

In this paper, the simple boost control of quasi-Z-source network is used [57]. The modulation and the capacitor voltage and inductor current of quasi-Z-source is shown in Fig. 17. When switch $S_{7}$ is turned on, the system works in nonshootthrough and the inductors charge the capacitors. The inductor current decreases and capacitor voltage increases, as shown in Fig. 17. When the switch $S_{7}$ is turned off, the system works in shoot-through mode and the inductors discharge the capacitors.

$I_{L_{1}}$ and $V_{C_{2}}$ are the average values of inductor current and capacitor voltage. $\Delta I_{L_{1}}$ and $\Delta V_{C_{2}}$ are the ripple amplitudes. Based on the quasi-Z-source operation theory, we know that the average voltage of the inductors over one switching period should be zero in steady state, so it has

$$
V_{C_{1}}=\frac{D}{1-2 D} V_{C_{0}} \quad V_{C_{2}}=\frac{1-D}{1-2 D} V_{C_{0}}
$$

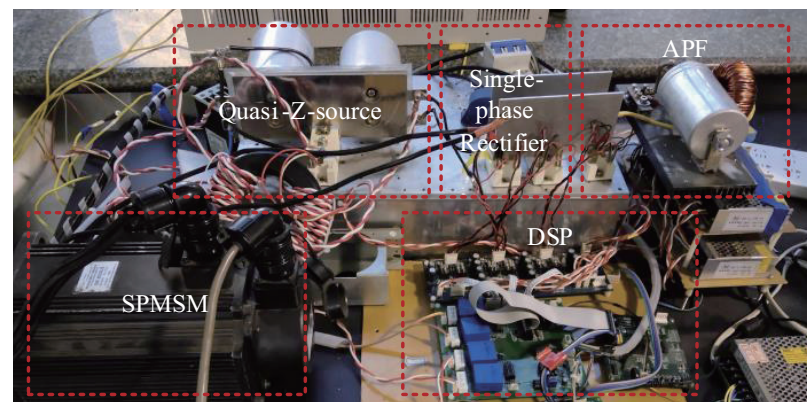

Fig. 18. Experimental setup.

TABLE I

MOTOR PARAmeters

\begin{tabular}{lc}
\hline \hline Parameter & Value \\
\hline Rated power & $4.7 \mathrm{~kW}$ \\
Rated voltage & $150 \mathrm{~V}$ \\
Rated current & $20.5 \mathrm{~A}$ \\
Rated torque & $23 \mathrm{~N} . \mathrm{m}$ \\
Rated speed & $2000 \mathrm{rpm}$ \\
$d$-axis inductance & $0.674 \mathrm{mH}$ \\
$q$-axis inductance & $0.674 \mathrm{mH}$ \\
Pole number & 4 \\
Winding resistance & $0.096 \Omega$ \\
Maximum current & $61.5 \mathrm{~A}$ \\
\hline \hline
\end{tabular}

where $D$ is the shoot-through duty ratio, $T_{s}$ is the carrier period. During the shoot-through state, this is the time period of $D T_{s} / 2$, the current and voltage can be calculated,

$$
v_{C_{2}}=L_{1} \frac{\mathrm{d} i_{L_{1}}}{\mathrm{~d} t} \quad i_{L_{2}}=-C_{1} \frac{\mathrm{d} v_{C_{1}}}{\mathrm{~d} t}
$$

Based on (18) and (19), the capacitor and inductor value ranges can be got,

$$
\begin{gathered}
L_{1}=L_{2} \geqslant \frac{D(1-D) V_{C_{0}}}{2(1-2 D) I_{L_{1}} \varepsilon_{i}} T_{s} \\
C_{1}=C_{2} \geqslant \frac{I_{L_{1}}(1-2 D)}{2 V_{C_{0}} \varepsilon_{v}} T_{s}
\end{gathered}
$$

where $\varepsilon_{i}$ and $\varepsilon_{v}$ are current and voltage ripple ratios, respectively.

\section{EXPERIMENTAL RESULTS}

In this section, a $2.2-\mathrm{kW}$ prototype is designed to verify the proposed new integrated charger. The experimental setup is shown in Fig. 18. The novel single-phase quasi-Zsource integrated charger proposed in this paper uses the motor windings as grid-side filter inductors in charging mode. According to the system power, input voltage, the current and voltage ripples of quasi-Z-source network, output voltage and the motor parameters, the APF circuit is designed. At last, the experimental results are given.

SPMSM is used in this system and the motor parameters are shown in Table I. As the motor windings are used as grid-side 


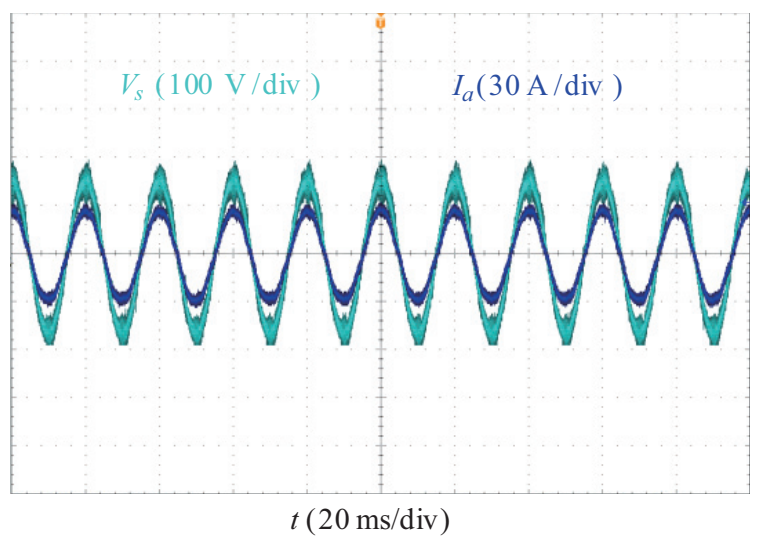

Fig. 19. Grid-side current and voltage.

filter inductors, the inductance of motor windings is important to charger under charging mode. According to (1), we can know that the inductance of each phase is $L_{a a}+M_{a b 0}$. And it has $2 M_{a b 0} \approx L_{a a} \approx L_{a a 0}=1 / 2\left(L_{d}+L_{q}\right)$. Therefore, in this system the inductance of each phase is about $1 \mathrm{mH}$. And the equivalent grid-side filter inductance is $1.5 \mathrm{mH}$ using the proposed integrated charger.

Then we need calculating the APF parameters. The input peak voltage is $V_{\mathrm{m}}=146 \mathrm{~V}$. As the rated current of SPMSM is $20.5 \mathrm{~A}$, the input current should be lower than $20.5 \mathrm{~A}$. So the peak current is chosen $I_{\mathrm{m}}=29$ A. The grid-side filter inductor is $L_{a}=1.5 \mathrm{mH}$. The resonant frequency range is $100 \mathrm{~Hz}$ to $1000 \mathrm{~Hz}$. According to (17), it has the maximum value of $C_{3}$ is $635 \mu \mathrm{F}$. To increase the power density of the system, the larger capacitor is better. And the current ripple of $C_{3}$ shouldn't be too high, the resonant frequency is chosen as $300 \mathrm{~Hz}$. We can get the value range of $C_{3}$ is $436 \mu \mathrm{F} \leqslant C_{3} \leqslant 617 \mu \mathrm{F}$. Based on practical considerations, we choose $560 \mu \mathrm{F}$ as capacitor $C_{3}$ value and $0.5 \mathrm{mH}$ as inductor $L_{3}$ value.

Because the application of APF circuit, the quasi-Z-source network only needs suppressing the carrier frequency ripples of inductor current and capacitor voltage. According to (20) and (21), the ripple ratios are chosen as $\varepsilon_{i}=20 \%$ and $\varepsilon_{v}=1 \%$. Then it can get the minimum inductance and capacitance of quasi-Z-source network are $0.84 \mathrm{mH}$ and $133 \mu \mathrm{F}$, respectively. The designed quasi-Z-source network parameters are suitable for integrated charger system. As the electric vehicle's power is larger than the charging power, the quasi-Z-source network parameters designed for traction mode are also suitable for that in charging mode. In this paper, to verify the theory, $1 \mathrm{mH}$ and $140 \mu \mathrm{F}$ are chosen as inductance and capacitance of the quasiZ-source network.

The grid-side current and voltage waveforms are shown in Fig. 19. The total harmonic distortion (THD) of the grid-side current is $1.46 \%$. And the system can works with unit power factor.

Fig. 20 gives the experimental results when the system does not use the APF. The inductor current ripple and capacitor voltage ripple of quasi-Z-source network are very large. The power losses of inductors and capacitors are high and the voltage stress and current stress of main switches are also very high. Large inductance and capacitance are needed to suppress

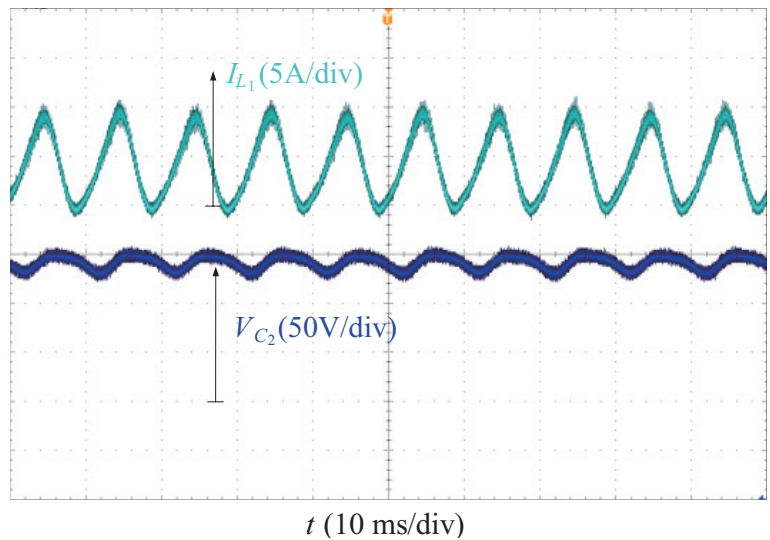

Fig. 20. Experimental results without APF: $L_{1}$ current and $C_{2}$ voltage.

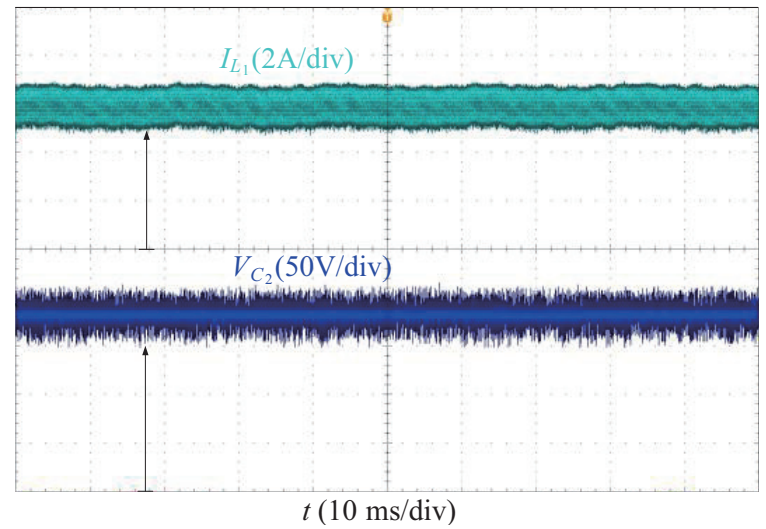

Fig. 21. Experimental results with APF: $L_{1}$ current and $C_{2}$ voltage.

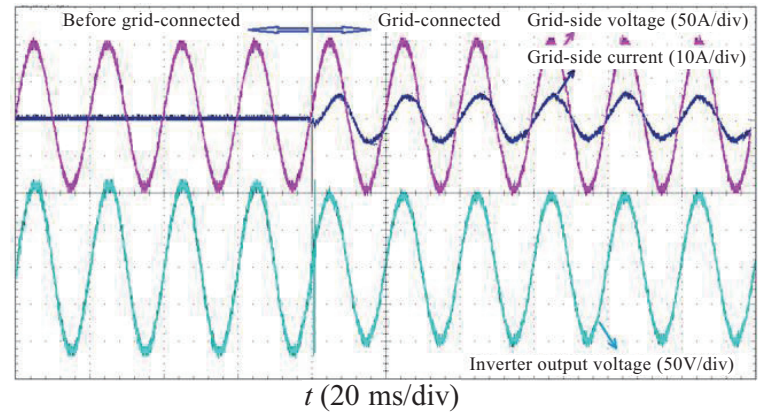

Fig. 22. Grid-connected experimental results: grid-side current and voltage and inverter output voltage.

the ripples. The cost and volume of system will increase. While, the current and voltage ripples are reduced when the APF circuit is used. Fig. 21 shows the current and voltage of the quasi-Zsource network. We can see that the ripples of the current and voltage have been suppressed. The APF absorbs all second harmonic ripples.

The integration technologies in motor drives is introduced in [58]. The integrated system proposed in this paper also achieves integration in motor drives.

Fig. 22 gives the grid-connected experimental results. When the system works in $\mathrm{V} 2 \mathrm{G}$ mode, the grid-side voltage and current are with the same phase. And the power factor is 0.992 . 


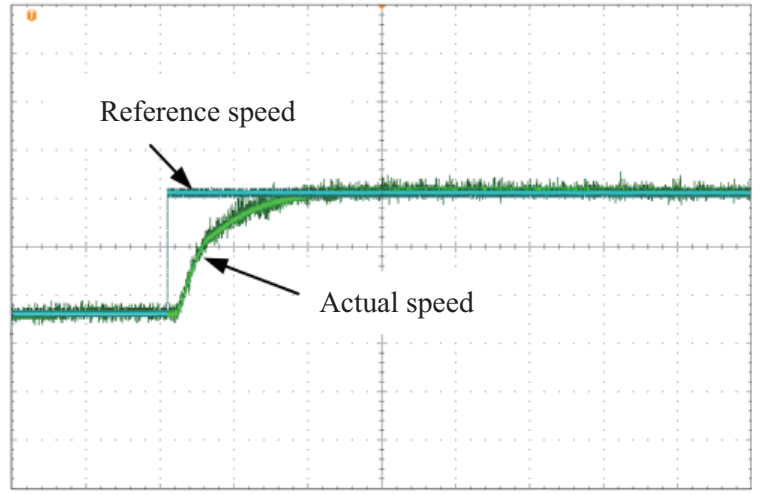

$t(10 \mathrm{~ms} / \mathrm{div})$

Fig. 23. Traction mode experimental results: reference and actual speed.

Fig. 23 gives the traction mode experimental results. From the Fig. 23 we can conclude that the advantages of the system are high response speed, small overshoot and tracking error.

\section{CONCLUSION}

In this paper, the topologies of the on-board integrated charger have been reviewed. And a novel single-phase integrated charger using quasi-Z-source network is proposed. The advantages of the proposed integrated charger are that the novel charger includes an APF circuit which can absorb all second harmonic ripple. The inductors and capacitors of the quasi-Z-source can be designed small. The proposed single-phase integrated charger uses the motor windings as gird-side filter inductor. The motor keeps still in charging mode. The PFC of the charger utilizes two bridges of the inverter. The proposed integrated charger reduces the size, weight and cost. The disadvantage is that the system needs additional capacitor and inductor to construct APF circuit. At last, a 2.2-kW prototype is designed.

\section{REFERENCES}

[1] M. Yilmaz and P. T. Krein, "Review of battery charger topologies, charging power levels, and infrastructure for plug-in electric and hybrid vehicles," in IEEE Transactions on Power Electronics, vol. 28, no. 5, pp. 2151-2169, 2013.

[2] N. Tuopu, Y. Xue, T. Jiaqi, and Z. Qianfan, "A Review of on-board integrated charger for electric vehicles and a new solution," IEEE 10th International Symposium on Power Electronics for Distributed Generation Systems (PEDG), pp. 692-699, 2019.

[3] S. Dusmez and A. Khaligh, "A compact and integrated multifunctional power electronic interface for plug-in electric vehicles," in IEEE Transactions on Power Electronics, vol. 28, no. 12, pp. 5690-5701, 2013.

[4] S. Ebrahimi, M. Tagliavi, F. Tahami, and H. Oraee, "A single-phase integrated bidirectional plug-in hybrid electric vehicle battery charger," in Industrial Electronics Society, IECON 2014 - 40th Annual Conference of the IEEE, 2014, pp. 1137-1142.

[5] J. Kim, I. Lee, and G. Moon, "Integrated dual full-bridge converter with current-doubler rectifier for EV charger," in IEEE Transactions on Power Electronics, vol. 31, no. 2, pp. 1-1, 2015.

[6] L. Young-Joo, A. Khaligh, and A. Emadi, "Advanced integrated bidirectional AC/DC and DC/DC converter for plug-in hybrid electric vehicles," in IEEE Transactions on Vehicular Technology, vol. 58, no. 8, pp. 3970-3980, 2009.

[7] H. Ruoyu and A. Emadi, "Integrated active power filter auxiliary power modules for electrified vehicle applications with single-phase on-board chargers," in Transportation Electrification Conference and Expo (ITEC), 2015 IEEE, 2015, pp. 1-6.

[8] D. B. W. Abeywardana, P. Acuna, B. Hredzak, R. P. Aguilera, and V. G. Agelidis, "Single-phase boost inverter-based electric vehicle charger with integrated vehicle to grid reactive power compensation," in IEEE Transactions on Power Electronics, vol. 33, no. 4, pp. 3462-3471, 2018.

[9] K. S. Vishnu and P. K. Preetha, "Single stage inverter integrated with battery for renewable energy harvesting," in 2017 Innovations in Power and Advanced Computing Technologies (i-PACT), 2017, pp. 1-6.

[10] K. A. Chinmaya and G. K. Singh, "A single-stage integrated charger for electric vehicles (EVs) and plug-in electric vehicles (PEVs) incorporating induction motor drive," in IECON 2018-44th Annual Conference of the IEEE Industrial Electronics Society, 2018, pp. 954-959.

[11] R. Hou and A. Emadi, "Applied integrated active filter auxiliary power module for electrified vehicles with single-phase onboard chargers," in IEEE Transactions on Power Electronics, vol. 32, no. 3, pp. 1860-1871, 2017.

[12] P. Fang Zheng, "Z-source inverter," in IEEE Transactions on Industry Applications, vol. 39, no. 2, pp. 504-510, 2003.

[13] S. A. Singh, G. Carli, N. A. Azeez, and S. S. Williamson, "Modeling, design, control, and implementation of a modified Z-source integrated PV/grid/EV DC charger/inverter," in IEEE Transactions on Industrial Electronics, vol. 65, no. 6, pp. 5213-5220, 2018.

[14] W. Li, Z. Yuan, B. Lai, and Q. Zhang, "A control method of three-phase Z-source integrated charger with motor windings," in 2018 13th IEEE Conference on Industrial Electronics and Applications (ICIEA), 2018, pp. 1721-1726.

[15] H. Yihua, S. Xueguan, C. Wenping, and J. Bing, "New SR drive with integrated charging capacity for plug-in hybrid electric vehicles (PHEVs)," in IEEE Transactions on Industrial Electronics, vol. 61, no. 10, pp. 5722-5731, 2014.

[16] W. Xiaoming, G. Chun, H. Yihua, C. Wenping, and C. Xiangping, “A novel battery charging control scheme for on-board charger integrated switched reluctance motor drive," in Transportation Electrification AsiaPacific (ITEC Asia-Pacific), 2014 IEEE Conference and Expo, 2014, pp. 1-6.

[17] S. R. Khayam Huseini, E. Farjah, N. Tashakor, and T. Ghanbari, "Development of an integrated switched-reluctance motor drive with battery charging capability for electric vehicle propulsion system," in Power Electronics, Drives Systems \& Technologies Conference (PEDSTC), 2015 6th, 2015, pp. 579-584.

[18] H. Kai-Wei, Y. Pei-Hsun, and L. Chang-Ming, “An EV SRM drive powered by battery/supercapacitor with G2V and V2H/V2G capabilities," in IEEE Transactions on Industrial Electronics, vol. 62, no. 8, pp. 4714-4727, 2015.

[19] Y. Hu, C. Gan, W. Cao, C. Li, and S. Finney, "Split converter-Fed SRM drive for flexible charging in EV/HEV applications," IEEE Transactions on Industrial Electronics, vol. 62, no. 10, pp. 6085-6095, 2015.

[20] L. Jianing, X. Guoqing, W. Bangming, B. JunFang, and W. Huijun, “A novel integrated switched reluctance motor drive with bi-directional inverter," in Industrial Technology (ICIT), 2014 IEEE International Conference on, 2014, pp. 885-889.

[21] J. Jiang and T. Xia, "An integrated charger with central-tapped winding switched reluctance motor drive," in 2017 IEEE 6th International Conference on Renewable Energy Research and Applications (ICRERA), 2017, pp. 870-874.

[22] L. Tian-Hua, C. Yi, Y. Pei-Heng, and C. Jui-Ling, "Integrated battery charger with power factor correction for electric-propulsion systems," in IET Electric Power Applications, vol. 9, no. 3, pp. 229-238, 2015.

[23] C. Shi, Y. Tang, and A. Khaligh, "A three-phase integrated onboard charger for plug-in electric vehicles," in IEEE Transactions on Power Electronics, vol. 33, no. 6, pp. 4716-4725, 2018. 
[24] C. Shi, Y. Tang, and A. Khaligh, "A single-phase integrated onboard battery charger using propulsion system for plug-in electric vehicles," in IEEE Transactions on Vehicular Technology, vol. 66, no. 12, pp. 1089910910, 2017.

[25] M. Truntič, T. Konjedic, M. Milanovič, P. Šlibar, and M. Rodič, "Control of integrated single-phase PFC charger for EVs," in IET Power Electronics, vol. 11, no. 11, pp. 1804-1812, 2018.

[26] B. T. Vankayalapati, R. Singh, and V. K. Bussa, "Two stage integrated on-board charger for EVs," in 2018 IEEE International Conference on Industrial Technology (ICIT), 2018, pp. 1807-1813.

[27] M. Marzouk, J. P. Ferrieux, D. Frey, and B. Sarrazin, "A shared traction drive and battery charger modes for plug-in hybrid electric vehicle application," in Power Electronics and Applications (EPE'14-ECCE Europe), 2014 16th European Conference on, 2014, pp. 1-10.

[28] W. Liangrong, L. Jianing, X. Guoqing, X. Kun, and S. Zhibin, "A novel battery charger for plug-in hybrid electric vehicles," in Information and Automation (ICIA), 2012 International Conference on, 2012, pp. 168173.

[29] M. A. Khan, I. Husain, and Y. Sozer, "Integrated electric motor drive and power electronics for bidirectional power flow between the electric vehicle and DC or AC grid," in IEEE Transactions on Power Electronics, vol. 28, no. 12, pp. 5774-5783, 2013.

[30] S. Dusmez and A. Khaligh, "Cost effective solutions to level 3 onboard battery chargers," in Applied Power Electronics Conference and Exposition (APEC), 2012 Twenty-Seventh Annual IEEE, 2012, pp. 21212127.

[31] S. Lacroix, E. Laboure, and M. Hilairet, "An integrated fast battery charger for electric vehicle," in Vehicle Power and Propulsion Conference (VPPC), 2010 IEEE, 2010, pp. 1-6.

[32] W. Lhomme et al., "Integrated traction/charge/air compression supply using three-phase split-windings motor for electric vehicles," in IEEE Transactions on Power Electronics, vol. 33, no. 11, pp. 10003-10012, 2018.

[33] H. J. Raherimihaja, F. Zhang, T. Na, and Q. Zhang, "An integrated charger using segmented windings of interior permanent magnet motor based on 3 phase with 9 windings," in 2018 13th IEEE Conference on Industrial Electronics and Applications (ICIEA), 2018, pp. 565-570.

[34] S. Haghbin, S. Lundmark, M. Alakula, and O. Carlson, "An isolated high-power integrated charger in electrified-vehicle applications," in IEEE Transactions on Vehicular Technology, vol. 60, no. 9, pp. 41154126, 2011.

[35] S. Haghbin, K. Khan, Z. Shuang, M. Alakula, S. Lundmark, and O. Carlson, "An integrated 20-kW motor drive and isolated battery charger for plug-in vehicles," in IEEE Transactions on Power Electronics, vol. 28, no. 8, pp. 4013-4029, 2013.

[36] S. Haghbin, S. Lundmark, M. Alakula, and O. Carlson, "Grid-Connected integrated battery chargers in vehicle applications: review and new solution," in IEEE Transactions on Industrial Electronics, vol. 60, no. 2, pp. 459-473, 2013.

[37] Z. Wang et al., "A dual-channel magnetically integrated EV chargers based on double-stator-winding permanent-magnet synchronous machines," in IEEE Transactions on Industry Applications, vol. 55, no. 2, pp. 1941-1953, 2019.

[38] L. Huang, "Low cost control of two three-phase PMSMs in integrated motor drives and battery chargers for electric vehicle application," in 2015 18th International Conference on Electrical Machines and Systems (ICEMS), 2015, pp. 1894-1897.

[39] W. Dong-Gyun, J. Dong-Myoung, and L. Byoung-Kuk, "On the feasibility of integrated battery charger utilizing traction motor and inverter in plug-in hybrid electric vehicles," in IEEE Transactions on Power Electronics, vol. 30, no. 12, pp. 7270-7281, 2015.

[40] S. Gui-Jia and T. Lixin, "A new integrated onboard charger and accessory power converter for plug-in electric vehicles," in Energy Conversion Congress and Exposition (ECCE), 2014 IEEE, 2014, pp. 4790-4796.
[41] S. Seung-Ki and L. Sang-Joon, "An integral battery charger for fourwheel drive electric vehicle," in IEEE Transactions on Industry Applications, vol. 31, no. 5, pp. 1096-1099, 1995.

[42] S. Q. Ali, D. Mascarella, G. Joos, and L. Tan, "Torque elimination for integrated battery charger based on two permanent magnet synchronous motor drives for electric vehicles," in IET Electric Power Applications, vol. 11, no. 9, pp. 1627-1635, 2017.

[43] I. Subotic, M. Jones, and E. Levi, "A fast on-board integrated battery charger for four-motor EVs," in Electrical Machines (ICEM), 2014 International Conference on, 2014, pp. 2066-2072.

[44] I. Subotic, N. Bodo, and E. Levi, "An EV drive-train with integrated fast charging capability," in IEEE Transactions on Power Electronics, vol. 31, no. 2, pp. 1461-1471, 2016.

[45] I. Subotic, N. Bodo, E. Levi, M. Jones, and V. Levi, "Isolated chargers for EVs incorporating six-phase machines," in IEEE Transactions on Industrial Electronics, vol. 63, no. 1, pp. 653-664, 2016.

[46] I. Subotic, N. Bodo, and E. Levi, "Integration of six-phase EV drivetrains into battery charging process with direct grid connection," in IEEE Transactions on Energy Conversion, vol. 32, no. 3, pp. 10121022, 2017.

[47] N. Bodo, E. Levi, I. Subotic, J. Espina, L. Empringham, and C. M. Johnson, "Efficiency evaluation of fully integrated on-board EV battery chargers with nine-phase machines," in IEEE Transactions on Energy Conversion, vol. 32, no. 1, pp. 257-266, 2017.

[48] Subotic. I, Bodo. N, Levi. E, Jones. M, "Onboard integrated battery charger for EVs using an asymmetrical nine-phase machine," in IEEE Transactions on Industrial Electronics, vol. 62, no. 5, pp. 3285-3295, 2015.

[49] M. S. Diab, A. A. Elserougi, A. S. Abdel-Khalik, A. M. Massoud, and S. Ahmed, "A nine-switch-converter-based integrated motor drive and battery charger system for EVs using symmetrical six-phase machines," in IEEE Transactions on Industrial Electronics, vol. 63, no. 9, pp. 5326$5335,2016$.

[50] A. S. Abdel-Khalik, A. Massoud, and S. Ahmed, "Interior permanent magnet motor-based isolated on-board integrated battery charger for electric vehicles," in IET Electric Power Applications, vol. 12, no. 1, pp. 124-134, 2018.

[51] S. Q. Ali, D. Mascarella, G. Joos, and L. Tan, "Torque cancelation of integrated battery charger based on six-phase permanent magnet synchronous motor drives for electric vehicles," in IEEE Transactions on Transportation Electrification, vol. 4, no. 2, pp. 344-354, 2018.

[52] K. A. Chinmaya and G. K. Singh, "Integrated onboard single-stage battery charger for PEVs incorporating asymmetrical six-phase induction machine," in IET Electrical Systems in Transportation, vol. 9, no. 1, pp. $8-15,2019$.

[53] J. Hong, H. Lee, and K. Nam, "Charging method for the secondary battery in dual-inverter drive systems for electric vehicles," in IEEE Transactions on Power Electronics, vol. 30, no. 2, pp. 909-921, 2015.

[54] C. Li, W. Huang, R. Cao, F. Bu, and C. Fan, "An integrated topology of charger and drive for electric buses," in IEEE Transactions on Vehicular Technology, vol. 65, no. 6, pp. 4471-4479, 2016.

[55] S. Semsar, T. Soong, and P. W. Lehn, "Integrated single-phase electric vehicle charging using a dual-inverter drive," in 2018 IEEE Transportation Electrification Conference and Expo (ITEC), 2018, pp. 320-325.

[56] T. Na, Q. Zhang, J. Tang, and J. Wang, "Active power filter for singlephase Quasi-Z-source integrated on-board charger," in CPSS Transactions on Power Electronics and Applications, vol. 3, no. 3, pp. 197-201, 2018.

[57] X. Fang, B. Ma, G. Gao, and L. Gao, "Three phase trans-quasi-z-source inverter," in CPSS Transactions on Power Electronics and Applications, vol.3, no.3, pp.223-231, September 2018.

[58] T. M. Jahns and H. Dai, "The past, present, and future of power electronics integration technology in motor drives," in CPSS Transactions on Power Electronics and Applications, vol.2, no.3, pp.197-216, Sept. 2017. 


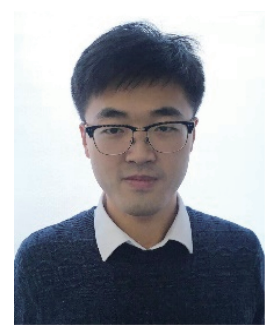

Tuopu Na received the B.S. and M.S. degree in Electrical Engineering from the Harbin Institute of Technology, Harbin, China, in 2012 and in 2014, respectively.

He is current a Ph.D. in the School of Electrical Engineering, Harbin Institute of Technology, Harbin, China. His research interests include electric vehicle integrated charger, Z-source converter/inverter, V2G technology, etc.

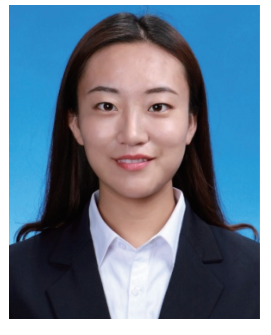

Xue Yuan was born in Heilongjiang Province, China She received the B.S. degree in Electrical Engineering from the YanShan University, Hebei, China, in 2018. She has been working toward the M.S. degree at Harbin Institute of Technology, China, since 2018. She specializes in the research field of power electronics for electric vehicle applications.

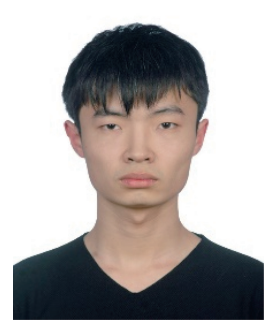

Jiaqi Tang received the B S. degree in 2016 from the Harbin Institute of Technology (HIT), Harbin, China, where he is currently working toward the Ph.D. degree with the Department of Electrical Engineering. He was focused on power electronics and electrical drive systems during his studies. His current research interests include the analysis, design, optimization, and control of wireless power transfer systems.

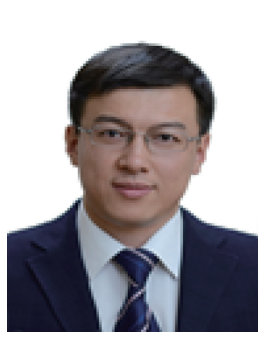

Qianfan Zhang was born in Heilongiiang province, China. He received B.S. and Ph.D. from the Harbin Institute of Technology, Harbin, China, in 1999 and 2004, respectively, both in Electrical Engineering.

In 1999, he joined Department of Electrical Engineering in Harbin Institute of Technology as a faculty. He is a professor since 2010 . His research interesting includes electric machine and drives, power electronics applied on EV, HEV, integrated charging system, and wireless power transfer system. 